\title{
EL TRIUNFO DEL DESENGAÑO. MARCO Y DESENGAÑO POSTRERO DE LA PARTE SEGUNDA DEL SARAO Y ENTRETENIMIENTO HONESTO, DE MARÍA DE ZAYAS
}

\author{
JOSÉ TERUEL \\ Universidad Autónoma de Madrid \\ jose.teruel@uam.es
}

$\mathrm{E}$ l estudio de la narrativa breve de doña María de Zayas y Sotomayor sigue avivando inevitablemente una cuestión, cuya respuesta, por muy parcial e incompleta que fuera, nos permitiría una mejor comprensión de la obra en sí. No sabemos casi nada de la vida de una autora que en su época fue tan leída como Cervantes. Su biografía es por ahora una narración borrada, que se nutre más de conjeturas e intuiciones que de datos constatables. De hecho, los únicos testimonios que dan fe de su vida son la partida bautismal, los testimonios muy mediatizados literariamente de algunos de sus contemporáneos y sus obras literarias.

Su partida de bautismo, extendida en la parroquia de San Sebastián de Madrid, el 12 de septiembre de 1590, nos informa del lugar y la fecha de su nacimiento, el nombre de sus progenitores y, consecuentemente, su condición social. Hija de don Fernando de Zayas y Sotomayor, caballero del hábito de Santiago, capitán de infantería, y de doña María de Carasa, aunque sobre la herencia materna ha habido sintomáticamente algún lapsus o variante, según el transcriptor. Manuel Serrano Sanz propone erróneamente en Apuntes para una biblioteca de escritoras españolas el nombre de Catalina de Barrasa (1905: 584), para transcribir seguidamente la partida bautismal con el nombre de María de Barasa (585), que ha sido unánimemente aceptado por la mayoría de sus estudiosos. Sin embargo, ya en el libro del padre Matías Fernández García nos encontrábamos con el apellido de Caraza (1995: 69). Ello nos llevó a consultar la fuente original: el Libro III de bautismos (fol. 213) de la mencionada parroquia madrileña, que confirma el apellido materno de Carasa (véase la imagen de la partida bautismal). 


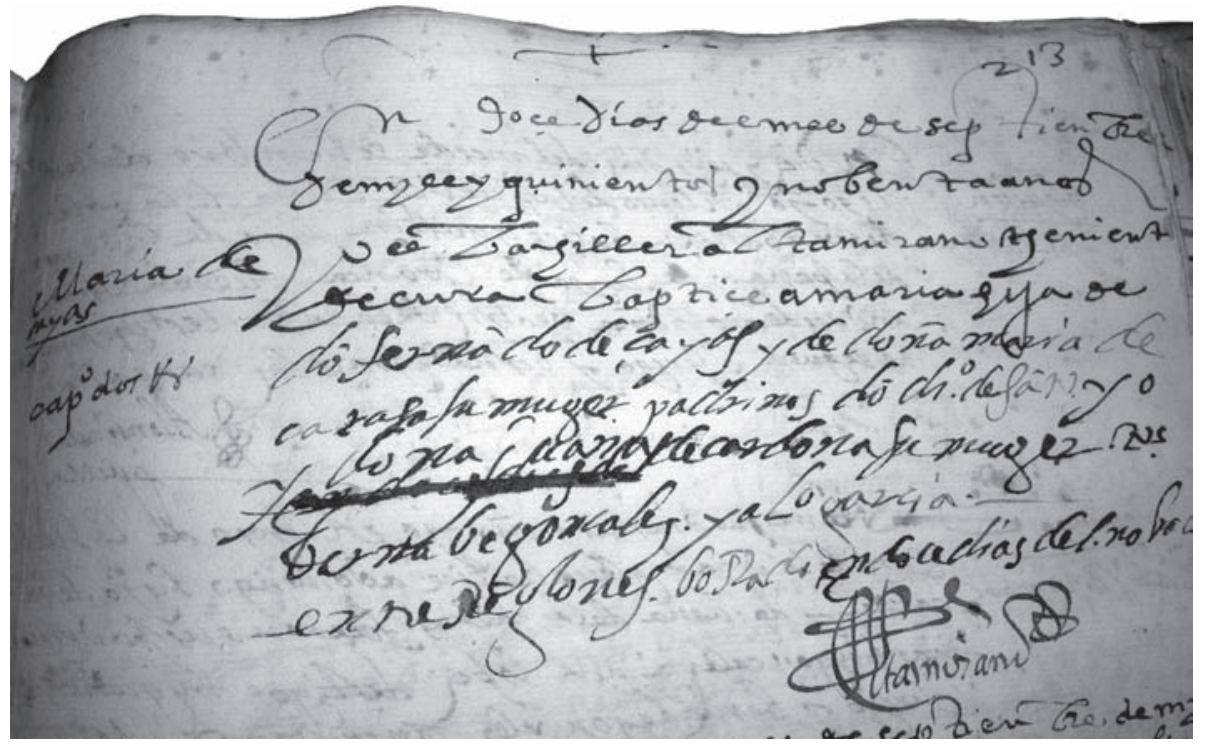

TRANSCRIPCIÓN: En doce días del mes de septiembre de mill y quinientos y nobenta años, yo el bachiller Altamirano, theniente de cura, bapticé a María, hija de don Fernando de Çayas y de doña María de Carasa su muger. Padrinos don Diego de Santoyo y doña Juana de Cardona su muger; testigos Bernabé Gonzalez y Alonso García. - Altamirano

(Parroquia de San Sebastián de Madrid, Libro 3 Bautismos, fol. 213. Cortesía del padre Pedro Pablo Colino)

Otros datos con los que contamos de su vida quedan ratificados en los preliminares de sus Novelas amorosas y ejemplares (1637), como son sus relaciones amistosas con Ana Caro Mallén, Juan Pérez de Montalbán, Alonso de Castillo Solórzano, su admiración por Lope de Vega, su concurrencia a las Academias madrileñas y su conocimiento en los mentideros literarios madrileños (Lope le había dedicado una conceptuosa estrofa, llamándola «ingenio vivamente claro / [...] único y raro» [2002: 258] y Castillo Solórzano la nombra «Sibila de Madrid» en La garduña de Sevilla [1942: 66]). Conocemos, gracias a Kenneth Brown, un vexamen del poeta secesionista catalán Francesc Fontanella para la Academia de Santo Tomás de Aquino de Barcelona (fechado el 15 de marzo de 1643) que pinta a Zayas como bastante hombruna. Al tratarse de una mención insultante, su capacidad de referencia fidedigna es discutible. De cualquier forma aquí queda este testimonio de dudoso gusto:

Doña María de Zayas

viu ab cara varonil, que a bé que «sayas» tenia 
bigotes filava altius.

Semblava a algun cavaller, mes jas' vindrà a descubrir que una espasa mal se amaga baix las «sayas» femenils.

En la dècima tercera fou glosadora infeliz, que mala tercera té quant lo pris vol adquirir. O Senyora Doña Saÿa, per premiar sos bons desitgs del sèrcol de un guardainfant tindrà corona gentil! ${ }^{1}$

(Fontanella apud Brown 1993: 358)

El resto de su vida son presunciones propias tanto de la sinergia como de la opaca relación entre arte y vida: su factible estancia en Nápoles, dada la servidumbre de su padre al noveno conde de Lemos y su más que probable soltería. Carmen Martín Gaite, al repasar el elenco de autoras recogido por Manuel Serrano y Sanz en sus citados Apuntes, observa el autodidactismo de estas escritoras y cómo sus trayectorias biográficas suelen ser irrelevantes, anodinas o simplemente desconocidas: «[...] Pocos datos dignos de mención se encuentran en la biografía de estas mujeres, que muchas veces ha de ser reconstruida imaginariamente, a través de las opiniones o descripciones que dejaron plasmadas en su obra» (1987: 25). Esta apreciación general nos interesa porque en el fondo le sirve para introducirnos en la falta de datos fiables sobre la particular vida de María de Zayas, de la que «ni siquiera se conoce la fecha de su muerte, ni los lugares donde habitualmente residió» (26). La razón que Martín Gaite esgrime, pensando en los hipotéticos viajes de la autora madrileña por diferentes puntos de España e Italia, vuelve a ser de validez general: las mujeres no solían dejar memoria en los sitios que hubiesen recorrido, ya que — a diferencia de la mayor parte de los varones de la épocano iban «en busca de aventuras, ni para desempeñar un cargo diplomático, ni para intervenir en ningún hecho de armas, empresas estas últimas lo suficientemente prestigiosas de por sí como para realzar la fama de quien, además manejara con destreza la pluma» (26). Las mujeres no dejaban fama: traspasar la frontera de lo público era transgredir las expectativas culturales. Se fomentaba tanto el

\footnotetext{
1 Ángeles Caso ofrece la siguiente traducción: «Doña María de Zayas / tiene rostro varonil, / y por más que lleve sayas / bigotes altivos luce. / Se parece a un caballero, / mas se vendrá a descubrir / que una espada mal se esconde / bajo saya femenil. / En la décimo tercera / fue glosadora infeliz, / que mala tercera tiene / si el premio quiere adquirir. / ¡Oh señora Doña Saya, / para premiar sus deseos, / del cerco de un guardainfante / tendrá corona gentil!» (2005: 133)
} 
encerramiento y el recato que llegaban a ser invisibles. En esto, como en tantas otras dimensiones, Teresa de Jesús y Sor Juana Inés de la Cruz fueron excepción. Sin embargo, lo que verdaderamente nos interesa tras estas apreciaciones generales es que Martín Gaite termine apuntando al mismo centro de la velada biografía de María de Zayas: «Tampoco se sabe si fue casada o soltera, guapa o fea» (26). Este conocimiento negativo le sirve para ensayar con despejo una afirmación muy privativa y probablemente cabal sobre el caso Zayas, apoyándose en el recurso genuinamente literario de algunos comentaristas y en una opinión constatada. Los supuestos comentaristas responden a la perspicaz intuición de la propia Carmen Martín Gaite quien sabía perfectamente, por su incursión en los Usos amorosos del siglo xviII y el primer franquismo, que «la extremada desigualdad entre los sexos tenía como compensación la extremada galantería con el sexo inferior» (Elliott apud Olivares 2000: 27) y la opinión constatada alude a la citada silva VIII de Laurel de Apolo de Lope de Vega:

A este respecto, algunos comentaristas señalaban que no debió destacarse por su belleza, y apoyan su conjetura en el hecho de que en ninguno de los elogios que hicieron de ella Lope de Vega y otros escritores de la época se hable más que de su «ingenio raro», pero no se canten alabanzas de su hermosura física, como hubiera aconsejado la más elemental galantería. Ya en esta puntualización se revela un prejuicio más de los muchos que tienden a mediatizar la labor de las mujeres y a marginarlas como seres pensantes con relación a los hombres, porque nadie ha tenido en cuenta, que yo sepa, el hecho de que Miguel de Cervantes tuviera un rostro noble o Quevedo fuera más feo que un dolor a la hora de rastrear sus respectivas biografías o valorar su obra (1987: 26).

La vida de María de Zayas continúa siendo en extremo oscura: este es el tópico ante el que todos sus exégetas se rinden, pero la mayoría de sus intérpretes también coincide en columbrar algún dato o hecho en su biografía que pese a su desconocimiento podría dilucidar algunas de sus pronunciadas desavenencias con las trilladas y convencionales resoluciones amorosas que conformaron los lugares comunes de la novela corta de su época y de tantas tramas de comedia, desavenencias que explican el prestigio actual de la escritora madrileña. ¿ De dónde proceden la exaltación de la amistad amorosa entre mujeres, la aparición de conductas sexuales femeninas con escasa representación en la literatura española de su época, el activísimo erotismo femenino en el que ha reparado toda la crítica (especialmente desde del ensayo que Juan Goytisolo publicara en 1972 en Cuadernos de Ruedo Ibérico), el amor masculino a los muchachos, la recurrente huida al convento como único lugar habitable para la mujer en sociedad tras haber conocido la experiencia amorosa masculina, la ruptura del final feliz y otros rasgos argumentales que iremos recogiendo en nuestro artículo? Todas estas desavenencias nos 
remiten al cultivo de una diferencia de orden literario con respecto a la tradición en la que se sitúa la autora: la literatura de entretenimiento en torno a los saraos que gozó de los favores de un público especialmente femenino (Bosse 1999: 251251), y también a una diferencia de orden biológico o biográfico, completamente velada a nuestro conocimiento y en la que solo cabe la conjetura, pero desde la que la autora se posiciona como demuestra su visión pesimista del amor, experiencia fatalmente unida al error, el desdén, los celos y sobre todo al código del honor varonil: «don Gaspar, más atento a su honor que a su gusto»; «Lo que me parece más conveniente [...] es que la mate su marido, y de esta suerte no culparán a nadie», leemos en situaciones y en boca de personajes distintos de «Estragos que causa el vicio» (Zayas 1983: 484 y 494).

María de Zayas coge la pluma con un triple y coincidente propósito: defender las capacidades intelectuales de la mujer, denunciar el encerramiento al que ha sido condenada como única instrucción y «desvelar las trampas del amor masculino» (Redondo 1989: 14), ante cuya fuerza no le cabe a la mujer otro amparo que la huida y el refugio en el convento. El discurso de Zayas llega a ser combativo, se apoya en la tesis de que hombres y mujeres tienen la misma alma, potencias y sentidos, pero estas no reciben la misma educación. Nuestra autora retoma el debate sobre «la querella de las mujeres» que en el siglo xvi estuvo centrado sobre la pertinencia de su educación. Extraigo dos citas espléndidas de Novelas amorosas y ejemplares que merecen ser recordadas como dos pioneras declaraciones publicadas en la España de 1637. La primera procede de «Al que leyere», un genuino umbral en la autobiografía de María de Zayas como escritora y un manifiesto de su entrada en la arena pública. La segunda, de la novela de la noche tercera, «La fuerza del amor»:

[...] La verdadera causa de no ser las mujeres doctas no es defecto del caudal, sino falta de la aplicación. Porque si en nuestra crianza, como nos ponen el cambray en las almohadillas y los dibujos en el bastidor, nos dieran libros y preceptores, fuéramos tan aptas para los puestos como los hombres (2010: 159-160).

[...] Por tenernos sujetas desde que nacemos, vais enflaqueciendo nuestras fuerzas con temores de la honra, y el entendimiento con el recato de la vergüenza, dándonos por espadas ruecas, y por libros almohadillas (2010: 364).

En los Desengaños amorosos (1647) da un paso más allá de esta defensa del poder igualatorio de la educación entre sexos y considera que, «tras la educación castradora, se oculta el temor de los hombres a la competencia femenina» (Yllera 1999: 231). La cita procede de «Tarde llega el desengaño»: «De manera que no voy fuera de camino en que los hombres de temor y envidia las privan de las letras y las armas, como hacen los moros a los cristianos que han de servir donde hay mujeres, que los hacen eunucos por estar seguros de ellos» (1983: 231). 
Nuestro trabajo se centrará en el análisis del discurso narrativo del marco de la Parte segunda del Sarao y entretenimiento honesto y del desengaño postrero. El título Desengaños amorosos no aparece en la cubierta de la colección hasta la edición de 1950 de Agustín González de Amezúa. En la edición de Barcelona (Sebastián de Cormellas, 1649) de la Parte segunda del Sarao, nos encontramos en la portada, tras «La esclava de su amante» (única novela que lleva título en todas las ediciones), el explícito rótulo para las nueve novelas restantes de «Desengaños de las damas, repartidas en varias noches». Un siglo más tarde, en la edición conjunta de las dos colecciones de Pedro Joseph Alonso y Padilla (Barcelona: 1734), la segunda parte se intitula Desengaños, y como comenta Alicia Yllera: «Va precedida de una portada independiente prevista, probablemente, para poder vender la obra en dos volúmenes» (1983: 73). Se infiere que la necesidad de publicar dos volúmenes sueltos haya generado la mayor conveniencia comercial por parte de los editores de buscar un título más distintivo y menos anodino para la Parte segunda, aunque no dudamos de que el rótulo Desengaños amorosos, con el que se edita desde 1950, es propiciado por la denominación con que la autora designa el género novella y concuerda con el leitmotiv de las distintas tramas.

Tras las Novelas amorosas y ejemplares se concertaron las bodas de Lisis con don Diego, pero desde las primeras líneas del marco de la nueva colección se anticipa el final: la dama cae enferma de una dolencia inconcreta, que la novela del siglo XIX explorará a través del tópico de la mujer insatisfecha. La prolepsis es evidente: en los momentos en que Lisis parecía recobrar la salud quiso «obrar en su alma nuevos propósitos» (116). «Más de un año le duró la enfermedad» (116) y durante su convalecencia demuestra cierta esquivez con don Diego. María de Zayas pone de manifiesto sus dotes inusitadas de observación y penetración psicológica, ya que Lisis ni estaba convencida de este matrimonio ni tampoco de lo contrario, solo después de escuchar los diez desengaños en boca de sus amigas y parientas se producirá el movere: la protagonista central del marco modificará «su proyecto vital» a consecuencia de lo atentamente escuchado (Riera y Cotoner 1987: 155).

Con la llegada de la «hermosísima» (116) Zelima, Lisis sale del aislamiento y recobra la salud gracias a los cantos, cuentos y «gallardo entendimiento» (117) de la falsa esclava. Ello permite escenificar dos cuestiones que no son de ningún modo secundarias: por un lado, cómo la mujer ideal nunca podrá ser hermosa y boba; y por otro, la amistad positiva entre mujeres fundada en sus capacidades de discernimiento. La autoconciencia narrativa de María de Zayas quedará patente en los principios enunciados desde el propio marco de la colección que nos disponemos a leer: «[S]e dispuso de esta suerte: en primer lugar, que habían de ser las damas las que novelasen (y en esto acertó con la opinión de los hombres, pues siempre tienen a las mujeres por noveleras)» (118). 
La primera característica de la enunciación en la Parte segunda del Sarao será el emisor femenino. Se concede a las mujeres el don de novelar y se les niega a los hombres. Frente al estereotipo de la frase latina Mulierem ornat silentium y frente al sexo locuaz, aquí se da la palabra a la mujer (convertida en relatora), lo que permite a María de Zayas hacer gala de su ironía, introduciendo su propia voz entre paréntesis en el enunciado narrativo (la voz de la autora del proceso sémico) para constatar una opinión ajena en torno a la concepción de las mujeres tachadas de noveleras, vocablo cuyo frecuente uso en femenino y clara significación despectiva alude a una supuesta tendencia de las mujeres en general a desorbitar la realidad: «[...] es parlera / y no menos novelera / de cosas nunca sabidas, / y relata las oydas / contino de otra manera», leemos ya en 1544 en el Diálogo de mujeres de Cristóbal de Castillejo (1986: 178). Ante este tópico propuesto para ser rechazado María de Zayas ironiza con lo que podría ser la significación literal del adjetivo noveleras o mujeres ansiosas de narración (esto es «que no se reconocían demasiado satisfechas en el seno de los argumentos rutinarios que formaban la trama de su vivir» [Martín Gaite 1988: 71]). Aunque Zayas también utiliza el término noveleros aplicado a los hombres o al vulgacho (1983: 504 y 506). Si en el primer punto de la Introducción quedó dispuesto que el emisor fuese femenino, inmediatamente se aborda la índole moral del mensaje artístico de sus narraciones, mensaje que yo me atrevería a calificar de feminista avant la lettre o, con más propiedad a la fecha, contra la aberrante tradición misógina del Examen de Ingenios para las Ciencias (1575) de Juan Huarte de San Juan (Rodríguez y Haro 1999: 58) y La perfecta casada (1583) de fray Luis de León:

[Y] en segundo, que los que refiriesen fuesen casos verdaderos, y que tuviesen nombre de desengaños (en esto no sé si los satisfizo, porque como ellos procuran siempre engañarlas, sienten mucho se desengañen). Fue la pretensión de Lisis en esto volver por la fama de las mujeres (tan postrada y abatida por su mal juicio, que apenas hay quien hable bien de ellas). Y como son los hombres los que presiden en todo, jamás cuentan los malos pagos que dan, sino los que les dan [...]; que lo cierto es que no hubiera malas mujeres si no hubiera malos hombres. No hablo con los que no lo fueren, que de la misma manera que a la mujer falsa, inconstante, liviana y sin reputación no se le ha de dar nombre de mujer, sino de bestia fiera, así el hombre cuerdo, bien intencionado, y que sabe en los mismos vicios aprovecharse de la virtud y nobleza a que está obligado, no será comprendido en mi reprensión; [...] advirtiendo que de las mujeres que hablaré en este libro no son de las comunes [...], sino de las no merecedoras de desdichados sucesos (1983: 118-119).

Reconocer el engaño o el error del amor masculino es el propósito didáctico del discurso narrativo de María de Zayas. El término maravillas de la primera colección es reemplazado por el de desengaños, acompañado además por una 
convención narrativa: el afán de veracidad, siguiendo el topos de la adtestatio rei visae o el argumento de la «cosa vista» para suscitar patetismo. De forma que la narradora se presentará como conocedora del caso, ya sea por el protagonista, un deudo o un testigo del mismo (Olivares 2000: 56). La ejemplariedad implica también una construcción artística, ya que si Zayas buscaba explícitamente a un público femenino — como demuestra el mencionado prólogo, «Al que leyere»—, encontró en las novelas cortas de tema amoroso y enredo el género de entretenimiento más idóneo y eficaz para dicho público. Lo testimonia un contemporáneo, Juan de Zabaleta en El día de fiesta por la tarde (1983: 387), y la propia autora, desde la Introducción a sus Novelas amorosas y ejemplares, evita el término novela, «título tan enfadoso que ya en todas partes le aborrecen» (2000: 168). Téngase en cuenta los decretos sobre la prohibición de imprimir novelas y comedias en los reinos de Castilla entre 1625 y 1634. Aceptamos la tesis de Julián Olivares de que el título original de la primera colección de Zayas pudo ser Honesto y entretenido Sarao y que el cambio se deba a una enmienda del editor, el librero aragonés Pedro Esquer, para aprovechar la popularidad de las Novelas ejemplares de Cervantes (2000: 117-118).

El psicologismo de María de Zayas tiene en este segundo punto del marco un aspecto significativo, ya que su propósito de arremeter contra el discurso misógino estará acompañado de otros empeños narrativos: evitar el maniqueísmo de la víctima santa frente al verdugo (aunque en los Desengaños amorosos será muy ostensible su intención de manifestar la crueldad masculina) y atender a la individualidad: «no es razón que, hablando en común, las midan a todas con una misma medida» (503), aduce Lisis al final de la colección. En tal sentido, la narradora nos facilita una posible clave de interpretación de «Estragos que causa el vicio», cuya protagonista desde el punto de vista moral será más Magdalena que Florentina; es decir la mujer no merecedora «de desdichados sucesos» (119).

Advertimos nuevamente, en este segundo punto, la aparición entre paréntesis de una voz que aclara e interrumpe el enunciado de los personajes de la cornice o de las distintas novelas, para presentarnos en primera persona la opinión de la autora. Esta intromisión podría interpretarse como un autobiografema, que no desentona con la continua necesidad de autonarración que exhiben sus personajes, especialmente los femeninos. Con estas marcas autobiográficas (o señales de la posición del autor con respecto a su mundo narrativo) María de Zayas personaliza un género narrativo estereotipado, al incorporar una visión individual y diferenciada con respecto a la vox pópuli o la representación masculina de la época (Redondo: 19). Del mismo modo, la ruptura zayesca con el recurrente final feliz de la novela de aventuras amorosas presupone también una mirada personal y desilusionada sobre la experiencia del amor en sociedad: un modo de dejar su propia marca entre los ropajes de la ficción. 
En el marco las voces dominantes son las de Lisis y una narradora omnisciente, ya en primera, ya en tercera persona. Entre estas tres instancias, así como entre las voces de las nueve restantes «desengañadoras», se deslizará y fracturará la opinión de la autora. Es muy significativo este parlamento de Lisis en el último tramo de la cornice de los Desengaños amorosos, donde la palabra de la escritora — o emisora real — se superpone y desplaza a la de la organizadora del sarao, ya que literalmente la significación del enunciado no se corresponde con la enunciadora ficticia. En este oportuno lapsus, María de Zayas nos da nuevamente una significativa señal de las marcas autorreferenciales o autobiografemas que empapan su discurso narrativo: la escritora contaba con 57 años de edad cuando publica los Desengaños y había transcurrido un decenio desde la aparición de la primera parte del sarao:

Y digo que ni es caballero, ni noble, ni honrado el que dice mal de las mujeres [...] Y en forma de desafío, digo que el que dijere mal de ellas no cumple con su obligación. Y como he tomado la pluma, habiendo tantos años que la tenía arrimada, en su defensa, tomaré la espada para lo mismo, que los agravios sacan fuerzas donde no las hay; no por mí, que no me toca, pues me conocéis por lo escrito, mas no por la vista, sino por todas, por la piedad y lástima que me causa su mala opinión (506-507).

Como en las Novelas amorosas y ejemplares se fijan la disposición temporal de la reunión y la identidad de las diez narradoras así como los vínculos que las unen con Lisis, pero las numerosas alteraciones en la dispositio que el lector encontrará después llevaron a Alicia Yllera a dos conjeturas: bien que se deban a enmiendas indebidas del primer impresor o el corrector, bien que el manuscrito, por razones desconocidas, no llegase a la imprenta perfectamente corregido y terminado por la autora (1983: 60-63). La información metanarrativa sobre el emisor, el mensaje, la composición o estructura externa de los Desengaños amorosos culmina con la necesidad recurrente en el discurso narrativo barroco de introducir a los auditores o lectores que se acomodan formando una especie de pequeño teatro:

Se previnieron músicos, y entoldaron las salas de ricas tapicerías, suntuosos estrados, curiosos escritorios, vistosas sillas y taburetes, aliñados braseros, [...] claros y resplandecientes faroles, muchas bujías, y sobre todo sabrosas y costosas colaciones, sin que faltase el amigo chocolate (que en todo se halla, como la mala ventura). [...] Acomodados todos en sus lugares, sin que faltase de los suyos el ingrato don Juan y el dichoso don Diego, y todos los hombres mal contentos de que, por no serles concedido el novelar, no podían dar muestras de las intenciones. Y quizá los que escriben deseosos de verse en ocasión de vengarse, como si a mí me importase algo, pues no les quito el entendimiento que Dios les dio [...] Y las damas contentas 
de que les llegase la ocasión de satisfacerse de tantos agravios como les hacen en sentir mal de ellas, y juzgar a todas por una [...], y los músicos dieron principio a la fiesta con este romance $[\ldots](120)$.

Esta presencia de los oyentes o lectores junto a la nueva injerencia de la voz de la autora (que hemos resaltado en cursiva) con comentarios de distinta índole acelera la sensación de continuidad entre el mundo real (del emisor y el destinatario del proceso sémico) y el mundo irreal o ficticio del enunciado (con las distintas narradoras y sus oyentes o espectadores). El volumen que adquiere el discurso o el mundo comentado en la ficción de María de Zayas es excepcional. Además del recurrente espejismo barroco, la finalidad de advertencia moral que otorga sentido a su narrativa hace que se acentúe la búsqueda y presencia del destinatario a quien continuamente se está invitando a participar en la representación (Carmen Martín Gaite concibió la búsqueda apasionada de ese tú como «el hilo conductor del discurso femenino, el móvil primordial para quebrar la sensación de arrinconamiento» [1987: 47]). Lo demuestra Zayas en su espléndido preliminar, «Al que leyere», que constituye una auténtica preparación del lector de sus Novelas amorosas y ejemplares: a quien literalmente convida. Me parece sumamente original y seductora esta concepción de la lectura como invitación y del lector como convidado, esto es como dispuesto a acompañarla a un útil recreo, dulce debate o entretenido aviso sobre el amor masculino. Evangelina Rodríguez Cuadros y María Haro Cortés lo han señalado acertadamente «Zayas acentúa, sobre todo en las desmesuradas intervenciones del mundo comentado de sus Desengaños, la relación conativa y persuasiva de las narradoras con respecto a un público [...] femenino» (1999: 87). La nota de invitación al sarao se resalta con la presencia obsequiosa del verso y la música. Comenta Elias Rivers que «la mezcla de prosa y versos en las novelas de Zayas se puede explicar sobre todo por la tradición de la novela pastoril y, quizá, por ser la autora una mujer particularmente aficionada a la música» (1999: 323). La lírica propicia un efecto de suspensión y variación que acrecienta la mezcla de códigos literarios y la polifonía de la novela corta. La combinación de música y poesía parece que facilita la entrada en un mundo más literaturizado y pauta la salida del entorno enunciativo de la cornice.

Entre los diez desengaños me detendré por su posición y significación en el titulado, desde la edición barcelonesa de Pablo Campins (1734), «Estragos que causa el vicio» (los nueve títulos ideados por Campins concuerdan con los que estampó doña María en su primera colección y en «La esclava de su amante», ya que convocan a una condición o se presentan como un diagnóstico). Como es habitual en el engarce de las sucesivas narradoras y novelas con el marco a lo largo de las tres noches de las carnestolendas, este último desengaño viene precedido 
por una vuelta al mundo comentado, pero con mayor desarrollo y beligerancia, tal como hacía prever el protagonismo de la voz de Lisis, "presidente del sarao» (469): «“¿Cuándo ha de desengañar la bien entendida, o la bachillera, que de todo habrá, la que quiere defender a las mujeres, la que pretende enmendar a los hombres, y la que pretende que no sea el mundo el que siempre ha sido?”» (469). La pregunta retórica no responde tanto a un preguntar algo como a un preguntarse por la exactitud de algo que ya se sabe y que se reproduce tipográficamente entre comillas, pues se trata de resaltar la captación irónica de una opinión ajena. Del mismo modo que el uso anterior de la voz novelera, la aparición aquí del término bachillera confirman cómo el acceso de las mujeres al mundo de «la cultura ha sido bloqueado por un imaginario negativo, una representación indigna de sí mismas» (Freixas 2000: 214). Lo atestiguan términos coetáneos que se asemejan en el carácter peyorativo de su significación: hembrilatinas, culta latiniparla, marisabidillas, preciosas ridículas:

[...] Y yo, como no traigo propósito de canonizarme por bien entendida, sino por buena desengañadora, es lo cierto que, ni en lo hablado, ni en lo que hablaré, he buscado razones retóricas, ni cultas; porque, de más de ser un lenguaje que con el extremo posible aborrezco, querría que me entendiesen todos, el culto y el lego; porque como todos están ya declarados por enemigos de las mujeres, contra todos he publicado la guerra.

Y así, he procurado hablar en el idioma que mi natural me enseña y deprendí de mis padres; que lo demás es una sofistería en que han dado los escritores por diferenciarse de los demás; y dicen a veces cosas que ellos mismos no las entienden (469-470).

Como prevención, Lisis adopta astutamente la estrategia de minimizarse, que tanto nos recuerda la confesión de Teresa de Jesús en el Libro de la vida: «basta ser mujer para caérseme las alas, cuanti más mujer y ruin» (cap. 10: 8). No quiere presentarse ni como santa ni como sabia y, en lugar de teorizar, insiste en el propósito moral que debe habitar la obra literaria, prestándole todo su sentido. Los principios éticos se funden con los estéticos y la crítica social se convierte una vez más en crítica literaria, ya que la ejecución artística de dicho propósito lleva a María de Zayas a través de la voz de Lisis a una defensa de un canon estético que se nutre de palabras de familia, del «escribo como hablo» del humanismo renacentista. Sin entrar en la cuestión del artificio que supone la retórica de un estilo natural y en los numerosos incumplimientos de esta promesa estilística a lo largo de la colección, cabría interpretar esta defensa como una señal de diferencia, como un claro guiño femenino, ya que - frente a los «escritores» y los «heroicos» y grandilocuentes «discursos» masculinos (470)— ella reclamará un lugar para su propio discurso, al que calificará expresivamente (y continuando con la estrategia 
de minimizarse) de «mi pobre jornalejo» (470). Recuérdese que el reproche fundamental dirigido a La culta latiniparla (1624) es la de utilizar un lenguaje oscuro (Profeti 1995: 239).

Así, noble auditorio, yo me he puesto aquí a desengañar a las damas y a persuadir a los caballeros para que no las engañen [...] Y yo misma he de ser el mayor desengaño, porque sería morir del engaño y no vivir del aviso, si desengañando a todas, me dejase yo engañar.

¡Ánimo, hermosas damas, que hemos de salir vencedoras! ¡Paciencia, discretos caballeros, que habéis de quedar vencidos y habéis de juzgar a favor que las damas os venzan! (470).

El propósito ejemplar de su alocución hace que la voz de Lisis ponga el acento en la persuasión de la interlocución. Tenemos la impresión de que su narración se alimenta del diálogo interpersonal entre las del mismo sexo y de una disputa entre los sexos contrarios. Prevalece la confianza en el valor del primer empeño: el que las damas se desengañen a sí mismas a través de lo oído o leído. La persuasión a los caballeros «para que no las engañen» parece un fin accesorio: «Pues, señoras, desengañémonos; volvamos por nuestra opinión; mueran los hombres en nuestras memorias, pues más obligadas que a ellas estamos a nosotras mismas» (222), proclamaba Nise la primera noche en «El verdugo de su esposa». El desengaño es el camino que conduce a la verdad y esta advertencia o lógica sacrificial hace que la narrativa de Zayas coincida con los procedimientos alegóricos de la música y el drama litúrgico barrocos (ver R. de la Flor, 2008); pero lo que más nos interesa anotar es la reiteración de la prolepsis inicial. La presidenta del sarao no puede ser indiferente a lo escuchado. Después de la narración de sus nueve invitadas, ella ya está conmovida y siente esa aceptación desilusionada o desengañada que provoca el reconocimiento de un error. El marco queda perfectamente ensamblado con las narraciones precedentes, ya que en él se consigue la persuasión completa a través de la conjunción de las tres operaciones discursivas de la retórica clásica: docere, delectare, movere. Por esta razón cuando Lisis vuelve a la cornice (o el lugar donde se aprehende y advierte el escarmiento de lo atentamente escuchado), justo antes y después del último desengaño, adopta un tono claramente beligerante: «pues por todas peleo» (470). Los desengaños narrados desencadenan el cambio de conducta de la organizadora del sarao. Ante la suerte que corren las mujeres, especialmente las casadas, Lisis renuncia al matrimonio con don Diego, opta por la soltería y se refugia como seglar en un convento:

Y así, vos, señor don Diego [...], advertid que no será razón que, deseando yo desengañar, me engañe; no porque en ser vuestra esposa puede haber engaño, sino porque no es justo que yo me fíe de mi dicha [...]. Pues si una triste vidilla tiene 
tantos enemigos, y el mayor es un marido, pues, ¿quién me ha de obligar a que entre yo en lid de que tantas han salido vencidas, y saldrán mientras durare el mundo, no siendo más valiente ni más dichosa? Vuestros méritos son tantos, que hallaréis esposa más animosa y menos desengañada, que aunque no lo estoy por experiencia, lo estoy por ciencia. Y como en el juego, que mejor juzga quien mira que quien juega, yo viendo, no solo en estos desengaños, mas en lo que todas las casadas me dan [...]; estoy tan cobarde, que, como el que ha cometido algún delito, me acojo a sagrado y tomo por amparo el retiro de un convento, desde donde pienso (como en talanquera) ver lo que sucede a los demás (507-509).

La negación del matrimonio y la entrada en el convento como causa y efecto tienen otro testimonio excepcional en la Respuesta a Sor Filotea (1691), de Sor Juana Inés de la Cruz, que es además una encendida defensa de la vocación intelectual de una mujer: «Entreme religiosa, porque aunque conocía que tenía el estado cosas [...], muchas repugnantes a mi genio, con todo, para la total negación que tenía al matrimonio, era lo menos desproporcionado y lo más decente que podía elegir [...]» (1978: 55). La huida al convento es un acto de dominio de sí mismo y de discernimiento muy acorde con los ideales neoestoicos de la primera mitad del siglo xviI. Lisis decide adoptar un papel de distanciada contempladora de la escena teatral del mundo, dada la esencia precaria de la felicidad y el conocimiento de la naturaleza engañosa del amor masculino, lo que equivale a decir del amor en sociedad. El escolio final con el que termina la colección en la voz y con la firma de doña María de Zayas y Sotomayor niega la perspectiva trágica, para un final razonablemente feliz en cuanto que afirma la autodeterminación de independencia de su personaje central: «No es trágico fin, sino el más felice que se pueda dar, pues codiciada y deseada de muchos, no se sujetó a ninguno» (510511). Varias críticas han señalado la significación de la vida en el claustro como única posibilidad de habitación propia para la mujer inclinada al estudio en la Edad Moderna. El retiro conventual implicaba una mayor posibilidad de libertad intelectual y autogobierno o «la búsqueda de otra compañía, 'la del esposo que no se cansa' y 'la convivencia con mujeres buenas'» (Riera y Cotoner: 158). En tal sentido, Lisis no se refugia sola en un convento, sino en compañía de una auténtica corte de peregrinas: Estefanía, Laura, doña Isabel y su madre. El dato me parece significativo, ya que permite vislumbrar una interpretación y corrobora un hecho. En el primer sentido, se asoma la posibilidad de atisbar una futura perspectiva donde la mujer no se describa exclusivamente desde el punto de vista de su relación con los hombres (como han demostrado Carme Riera y Luisa Cotoner [158-159] hay esbozos valiosísimos en los Desengaños amorosos de amistad positiva entre mujeres; y Virginia Woolf, leyendo Life's Adventure de Mary Carmichael, nos advierte con desenfado e ironía de la normalidad de lo que nunca es esencial: «Do not start. Do not blush. Let us admit in the privacy of our own 
society that these things sometimes happen. Sometimes women do like women» [2004: 95]). Por otro lado, esta peregrinación de mujeres es también la confirmación de que el convento no era un lugar de encierro, especialmente cuando la que ingresaba pertenecía a la nobleza (baste citar al personaje de Jacinta en sus Novelas amorosas: «Aventurarse perdiendo»):

Los claustros, que las narradoras, horrorizadas por las violencias del famoso «deseo», escogen para sus refugios, corresponden más bien al tipo de espacios de comunicación social y culta. Existían como tales preferentemente antes del Concilio de Trento y de las reformas teresianas. En aquella época convivían aparentemente, sin grandes problemas, confesas ascéticas y dueñas de salón (o seglares) hostiles a los rigores del matrimonio («esquivas») o aun víctimas de un marido, con las abandonadas por un seductor/amante (tipo don Juan) e incluso las renegadas por el rey. Era allí donde, además, se les garantizaba una cierta reciprocidad equilibrada («casta») en el terreno de la comunicación entre los sexos. Todo eso terminó en España a más tardar en 1631 (Bosse: 269).

María de Zayas heredó y tuvo arraigados prejuicios propios de su casta que se afirman en su obra (sirva de ejemplo la visión de los criados y criadas como «animales caseros y enemigos no excusados» [508]). Incluso nos propuso a través de Lisis un extraño paralelismo entre la persecución a las mujeres, el relajamiento de costumbres y obligaciones de la nobleza y la decadencia del imperio, que nos recuerda por su ingenuidad e ineficacia los emplastos de los arbitrios (505-506). Pero, por encima de ese aristocratismo y esta añoranza el pasado, también nos legó en «Estragos que causa el vicio» una de las representaciones más cruentas, macabras y absurdas por su desmesura del sentido del honor varonil. «Aunque sea originariamente el deseo sexual de la mujer el que genera la idea de una acción criminal», el gran protagonista de la novela es — como analiza Monika Bosse- el «código del honor masculino que, una vez [supuestamente] ofendido, exige para ser restituido actos de venganza monstruosos y perversos» (292). Alicia Yllera refiere en su edición alguna noticia de semejantes venganzas en la época: «En los Avisos de Pellicer se narra cómo, en Córdoba, un marido, no contento con matar a su mujer, dio muerte también a todos los criados e incluso al perro, al loro y al mono, historia que parece haber inspirado a Lope de Vega su obra Los comendadores de Córdoba» (1983: 482n). Pero no recordamos en la literatura de los Siglos de Oro una matanza tan injusta y monstruosa, como la de la última novela de María de Zayas. El rigor absurdo del honor varonil «se dirige» no solo contra la mujer, sino también «contra los varones» y «contra la vida en su totalidad» (Bosse: 292): «Finalmente, en la casa no había cosa viva» (482), o «ya no quedaba nada vivo en casa» (499), se insiste doblemente ya desde la perspectiva del gobernador y sus acompañantes, ya desde la autonarración de la adúltera Florentina. La guerra 
a la cual están llamadas las mujeres se enfoca en esta novela contra el absurdo sistema nacional del honor varonil (Bosse: 297), del que son también cómplices ellas mismas.

Eros se convierte en Zayas en el dios de la Muerte: «en un autómata de la destrucción» (Bosse: 292). La única verdad del amor radica en su trampa. Las afirmaciones a lo largo de la novela son redundantes tanto en boca de la autora como en la de sus narradoras-personajes: «pues a mi parecer, ¿¿qué mayor perdición que enamorarse?» (475); «(con tan rigor hace amor sus tiros, cuando quiere herir de veras)» (475); «(que este tirano enemigo de nuestro sosiego tiene unos repentinos accidentes, que si no matan, privan de juicio a los heridos de su dorado arpón)» (476); «el amor es enfermedad, pues se pierde el gusto, se huye el sueño y se apartan las ganas de comer» (487); «Yo quería a quien no me quería, y éste amaba a quien yo tenía obligación de no ofender. ¡Válgame Dios! ¡Qué intrincado laberinto [...]!» (487). Las narradoras y asistentes (incluidos los lectores de los Desengaños amorosos) son en realidad partícipes de un debate sobre el amor en sociedad: un invento esencialmente androcéntrico que requiere una reinvención, pero para ello habría que reinventar al hombre, y mientras llega esa ansiada utopía la inmediata y única salida propuesta es la peregrinación al convento, concebido como una especie de paréntesis del patriarcado.

Recibido: 15/09/2014

Aceptado: 25/10/2014

BiBLIOGRAFÍA

Bosse, Monika (1999). «El sarao de María de Zayas y Sotomayor: una razón (femenina) de contar el amor». En Bosse M., Barbara Potthast y André Stoll (eds.), La creatividad femenina en el mundo barroco hispánico. Vol. I. Kassel: Edition Reichenberger, pp. 239-299.

Brown, Kenneth (1993). «María de Zayas y Sotomayor: Escribiendo poesía en Barcelona en época de guerra (1643)». Dicenda. Cuadernos de Filología Hispánica, 11, pp. 355-360.

CAso, Ángeles (2005). Las olvidadas. Una historia de mujeres creadoras. Barcelona: Planeta.

Castillejo, Cristóbal de (1986). Diálogo de mujeres [1544]. Rogelio Reyes Cano (ed.). Madrid: Castalia.

Castillo Solórzano, Alonso de (1942). La garduña de Sevilla y anzuelo de las bolsas [1642]. Federico Ruiz Morcuende (ed.), 2. ${ }^{a}$ ed. Madrid: Espasa-Calpe, Clásicos Castellanos.

Fernández García, Matías (1995). Parroquia madrileña de San Sebastián. Algunos personajes célebres. Madrid: Caparrús. 
FreIXAs, Laura (2000). Literatura y mujeres. Escritoras, público y crítica en la España actual. Barcelona: Destino.

Martín Gaite, Carmen (1987). Desde la ventana. Enfoque femenino de la literatura española. Madrid: Espasa Calpe.

(1988). El cuento de nunca acabar. $4^{\mathrm{a}}$ ed. Barcelona: Anagrama.

Olivares, Julián (2000). «Introducción». En María de Zayas y Sotomayor, Novelas amorosas y ejemplares. Madrid: Cátedra, pp. 9-147.

Profeti, Maria Grazia (1995). «Mujer y escritura en la España del Siglo de Oro». En Iris M. Zavala (coord.), Breve Historia feminista de la Literatura española (en lengua castellana). II. La mujer en la Literatura española. Modos de representación desde la Edad Media hasta el siglo XVII. Barcelona: Anthropos, pp. 235-284.

Redondo, Alicia (1989). «Introducción». En María de Zayas, Tres novelas amorosas y tres desengaños amorosos. Madrid: Castalia - Instituto de la Mujer, pp. 7-44.

Riera, Carme y Luisa Cotoner (1987). «Los personajes femeninos de María de Zayas, una aproximación». En María Ángeles Durán y José Antonio Rey (eds.), Actas de las cuartas jornadas de investigación interdisciplinaria. Literatura y vida cotidiana. Zaragoza: Seminario de Estudios de la Mujer - UAM, pp. 149-159.

Rivers, Elias L. (1999). «María de Zayas como poeta de los celos». En Bosse Monika, Barbara Potthast y André Stoll (eds.), La creatividad femenina en el mundo barroco hispánico. Vol. I. Kassel: Edition Reichenberger, pp. 323-333.

Rodríguez Cuadros, Evangelina y María Haro Cortés (1999). «Introducción». En María de Zayas, Leonor de Meneses y Mariana de Carvajal, Entre la rueca y la pluma. Novela de mujeres en el Barroco. Madrid: Biblioteca Nueva, pp. 7-138.

FLor, Fernando R. de la (2008). «Alegoría cristiana en el Barroco». En Il trionfo del Tempo e del Disinganno. Georg Friedrich Händel. Madrid: Teatro Real.

Sor JuANA InÉs DE LA CRUz (1978). «Respuesta de la poetisa a la muy ilustre Sor Filotea de la Cruz» [1691]. En Selección. Luis Ortega Galindo (ed.). Madrid: Editora Nacional.

SERrano y SAnZ, Manuel (1905). «Zayas y Sotomayor (D ${ }^{a}$. María de)». En Apuntes para una biblioteca de escritoras españolas desde el año 1401 al 1833. T. II., segunda parte. Madrid: BAE, pp. 583-620 [reed. Madrid: Atlas, 1975, pp. 583-620].

VeGA, Lope de (2002). Laurel de Apolo [1630]. Christian Giaffreda (ed.), Maria Grazia Profeti (intr.). Florencia: Alinea.

Woolf, Virginia (2004). A Room of One’s Own [1928]. Londres: Penguin Books.

YllerA, Alicia (1983). «Introducción». En María de Zayas y Sotomayor, Parte segunda del Sarao y entretenimiento honesto [Desengaños amorosos]. Madrid: Cátedra, pp. 11-110.

(1999). «María de Zayas: ¿una novela de ruptura?». En Bosse Monika, Barbara Potthast y André Stoll (eds.), La creatividad femenina en el mundo barroco hispánico. Kassel: Edition Reichenberger, vol. I, pp. 221-237.

Zayas y Sotomayor, María de (1983). Parte segunda del Sarao y entretenimiento honesto [Desengaños amorosos] [1647]. Alicia Yllera (ed.). Madrid: Cátedra.

ZAYAS y SOTOMAYOR, María de (2000). Novelas amorosas y ejemplares [1637]. Julián Olivares (ed.). Madrid: Cátedra. 


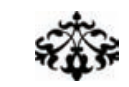

El triunfo del Desengaño. Marco y desengaño postrero

de la Parte Segunda del Sarao y entretenimiento honesto, de María de Zayas

RESUMEN : El artículo se inicia con una aclaración sobre el lapsus en la transcripción del apellido materno de la escritora María de Zayas (esta explicación es todo un indicio de cómo la mujer solía carecer de historia pública que contar), pero se centra en el examen de la conciencia narrativa de la autora a través de cuatro principios enunciados desde el marco narrativo de Desengaños amorosos: 1) la elección de emisoras femeninas; 2) la índole del mensaje de sus narraciones, al que cabe calificar de feminista avant la lettre; 3) la presencia en el enunciado de autobiografemas o señales de la posición de la autora con respecto a su mundo narrativo; y 4) las estrategias desarrolladas en el discurso para persuadir al interlocutor, principalmente al femenino. Entre los diez desengaños me detendré por su posición y significación en «Estragos que causa el vicio», cuyo protagonista será el rigor destructor del código del honor varonil.

Palabras clave: Zayas, Desengaños amorosos, «Estragos que causa el vicio», Marco narrativo, Autobiografemas, Interlocución femenina, Huida al convento.

\section{Disillusion Triumphant. FRAMEWORK and FINAL DISILLUSION IN MARÍa DE ZaYAS' PARTE SEGUNDA DEL SARAo y ENTRETENIMIENTO hONESTO}

AвSTRACT: The article begins with a clarification about the transcription of the maternal surname of the writer María de Zayas (this serves as an indication of how women often had no biographical details to relate), but focuses on the analysis of the author's narrative conscience by examining four principles which inform the narrative framework of Desengaños amorosos: 1) the choice of female speakers, 2) the nature of the message of their narrations, which could be called feminist avant la lettre, 3) the presence in the narrative of autobiographemes or indications of the author's stance with regard to her narrative world, and 4) the strategies marshalled in the text to persuade the reader, particularly the female reader. Of the ten "desengaños" I will focus on the final one "Estragos que causa el vicio», whose protagonist will succeed in destroying the code of masculine honor, because of its position and significance.

KEYwords: Zayas, Desengaños amorosos, «Estragos que causa el vicio», Narrative framework, Autobiographemes, Female Dialogue, Flight to the Convent. 


\section{EDAD DE ORO}

Revista de Filología Hispánica XXXIII

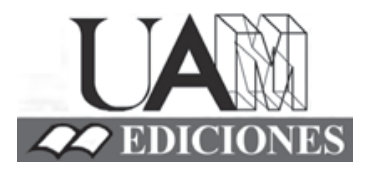


Evangelina Rodríguez Cuadros (Universitat de València)

Novela cortesana, novela barroca, novela corta: de la incertidumbre al canon 9

Mita Valvassori (Universidad de Los Lagos)

El modelo narrativo del Decamerón en la Edad de Oro: una vieja historia .21

Antonio Gargano (Università degli Studi di Napoli Federico II)

«Difficile est proprie communia dicere»: el género de la novella entre

Boccaccio y Cervantes

Guillermo Carrascón (Università degli Studi di Torino)

Apuntes para un estudio de la presencia de Bandello en la

novela corta del siglo XVII

Leonardo Coppola (Università degli Studi «G. d'Annunzio» di Chieti-Pescara)

La proyección de Straparola en la novela española del Siglo de Oro desde una perspectiva editorial

Mireia Aldomà García

Didactismo, género literario y lector en Giraldi Cinzio

María Jesús Zamora (Universidad Autónoma de Madrid)

«...En tiempo menos discreto que el de agora, aunque de hombres más sabios, se

llamaban a las novelas cuentos». La novela corta y el cuento en el Siglo de Oro......109

Marcial Rubio (Università degli Studi «G. d'Annunzio» di Chieti-Pescara)

La contribución de Cervantes a la novela barroca: la ejemplaridad.

Pierre Darnis (Université Bordeaux Montaigne)

La fuerza de la sangre, La ilustre fregona $y$ Las dos doncellas: ¿tres tipos

folclóricos?

María Soledad Arredondo (Universidad Complutense de Madrid)

De La gitanilla a La sabia Flora malsabidilla. El género, el personaje

y el matrimonio

Antonella Gallo (Università degli Studi di Verona)

Fabulaciones en equívocos burlescos: la Chrónica del monstro imaginado (1615)

de Alonso de Ledesma y novela corta barroca

David González Ramírez (Universidad de Málaga)

El filósofo del aldea (1625) de Baltasar Mateo Velázquez: recepción textual

e hipótesis autorial.

JONATHAN BRADBURY (University of Exeter)

La narrativa breve en la miscelánea del siglo XVII... 
Cristina Castillo Martínez (Universidad de Jaén)

«La fuente del desengaño»: de las Noches de invierno de Eslava a la Tercera

Diana de Tejeda.

MARÍA Zerari (Université Paris-Sorbonne, CLEA)

Furor in fabula: La cruel aragonesa de Castillo Solórzano (o de la dama monstruo).. 241

Giulia Giorgi (Università degli Studi di Ferrara)

Alonso de Castillo Solórzano reescritor de sí mismo: algunas notas sobre los

Escarmientos de amor moralizados y el Lisardo enamorado .257

Angela Fabris (Alpen-Adria-Universität Klagenfurt)

El diálogo con el público y los espacios reales y de maravilla en

Casos prodigiosos y cueva encantada de Juan de Piña 267

María Rocío LePe García (IES San Sebastián, Huelva)

La traducción inglesa de Hipólito y Aminta: una adaptación

con fines comerciales 281

Andrea Bresadola (Università degli Studi di Udine)

La novela española en la Italia del siglo XVII: el caso de Il Feniso

de Francisco de Quintana.

José Teruel (Universidad Autónoma de Madrid)

El triunfo del Desengaño. Marco y desengaño postrero de la Parte segunda

del Sarao y entretenimiento honesto, de María de Zayas

Nieves Romero-Díaz (Mount Holyoke College)

Lecturas alternativas en la Novela del fin bueno en mal principio

de doña Ana Francisca Abarca de Bolea....

ShIFra Armon (University of Florida)

Compromiso y distanciamiento en La Venus de Ferrara

de Mariana de Carvajal Saavedra

Mechthild Albert (Rheinische Friedrich-Wilhelms-Universität Bonn)

Las "noches": un subgénero novelístico en perspectiva comparada.... .365

Fernando Copello Jouanchin (Université du Maine, Le Mans)

El mueble en la novela corta del Siglo de Oro: algunas reflexiones

en torno a la cama

Ilaria Resta (Università del Salento):

De la novella al entremés pasando por la novela corta: reescrituras del cuento

La gara delle tre mogli del Cieco di Ferrara. 